\title{
Sexualidade na Deficiência Intelectual: uma Análise das Percepções de Mães de Adolescentes Especiais ${ }^{1}$ Sexuality in Intellectual Disabilities: an Analysis of the Perceptions of Mothers of Special Adolescents
}

\author{
Patrícia Mattos Caldeira Brant LITTIG $^{2}$ \\ Daphne Rajab CÁRDIA ${ }^{3}$ \\ Luciana Bicalho REIS ${ }^{4}$ \\ Erika da Silva FERRÃO ${ }^{5}$
}

\begin{abstract}
RESUMO: Adolescência é a fase transitória entre infância eidade adulta, momento importante do desenvolvimento humano, marcado por mudanças físicas, psicológicas e sociais relativas ao início da sexualidade. Este momento geralmente é conturbado e o poderá ser ainda mais para adolescentes com deficiência intelectual (DI) por confrontar com preconceitos e mistificações estabelecidas há tempos. A maneira infantilizante e discriminatória de serem tratados pela família e sociedade influenciam as percepções das mães de filhos com DI. Assim, objetivando investigar as concepções que mães de jovens com DI têm sobre a sexualidade deles e como elas irão refletir na adoção de práticas de educação sexual, foram entrevistadas 20 mães de adolescentes entre 12 a 18 anos, de ambos os sexos, com diagnóstico de DI, atendidos numa clínica escola localizada no estado do Espírito Santo. Analisando as entrevistas, percebeu-se em 12 respostas, a ideia de ausência de sexualidade na pessoa com DI, trazendo uma postura infantilizadora e superprotetora dessas mães em relação aos filhos, considerando-os com pouca possibilidade de desenvolver interesses e comportamentos sexuais. Quanto às concepções das mães nas manifestações sexuais de seus filhos, 15 delas revelaram entender que a sexualidade deles é diferente da de pessoas sem deficiência intelectual. Percebeu-se que 12 das 20 mães nunca orientaram seus filhos sexualmente, alegando que não compreenderiam. Em geral, as mães não reconhecem uma identidade sexual em seus filhos e, por conseguinte, não fornecem uma educação sexual, reproduzindo a concepção social e cultural que nega a existência da sexualidade quando associada à DI.
\end{abstract}

PALAVRAS-CHAVE: Educação Especial. Deficiência Intelectual. Sexualidade. Educação Sexual.

ABSTRACT: Adolescence is the transitional phase between childhood and adulthood, an important moment of human development, marked by physical, psychological and social changes at the beginning of sexuality. This moment is often troubled and may be even more so for teenagers with intellectual disability (ID) by confronting preconceptions and mystification established long ago. The infantilizing and discriminatory way they may be treated by family and society influence the perceptions of mothers of children with ID. Thus, to investigate the

\footnotetext{
${ }^{1}$ Apoio financeiro: Programa Institucional de Bolsas de Iniciação Científica e Tecnológica da Fundação de Amparo à Pesquisa do Espírito Santo (FAPES), vinculado à instituição privada de Ensino Superior do Centro Universitário Vila Velha (UVV) do estado do Espírito Santo - PIBICES-FAPES/UVV.

${ }^{2}$ Bolsista do Programa Institucional de Bolsas de Iniciação Científica e Tecnológica da Fundação de Amparo à Pesquisa do Espírito Santo (PIBIC-ES/FAPES). Acadêmica de Psicologia do Centro Universitário Vila Velha (UVV). pmcbrant@yahoo.com.br

${ }^{3}$ Voluntária do Programa Institucional de Bolsas de Iniciação Científica e Tecnológica da Fundação de Amparo à Pesquisa do Espírito Santo (PIBIC-ES/FAPES). Acadêmica de Psicologia do Centro Universitário Vila Velha (UVV). daphne_r_c@hotmail.com

${ }^{4}$ Doutoranda no Programa de Pós Graduação em Psicologia (UFES). Mestre em Psicologia (UFES). Docente do Curso de Psicologia do Centro Universitário Vila Velha (UVV). lucianabreis@hotmail.com

${ }^{5}$ Pós-Doutoranda no Programa de Pós-Graduação em Processos de Desenvolvimento e Saúde (UNB). Doutora em Psicologia (UFES). Docente do Curso Latu Sensu de Neuropsicologia e Reabilitação Cognitiva do Centro Universitário Vila Velha (UVV). edsferrao@yahoo.com.br
} 
conceptions that mothers of young people with ID have about their sexuality and how they will reflect the adoption of sexual education practices, 20 mothers of adolescents aged 12 to 18 years, of both sexes with a diagnosis of ID were interviewed at a clinical school located in the state of Espírito Santo. Analyzing the interviews, 12 answers indicated the idea of absence of sexuality in the person with ID, fostering an infantilized and overprotective attitude of these mothers to their children; it was considered unlikely that they would develop interest in sex or present sexual behaviors. As for the conceptions of mothers on the sexual manifestations of their children, 15 of them revealed understanding that their sexuality is different from that of people without intellectual disability. It was noted that 12 of the 20 mothers had never oriented their children about sex, saying they would not be capable of understanding. In general, the mothers do not recognize a sexual identity in their children and, therefore, do not provide them with sexual education, reproducing the social and cultural concept that denies the existence of sexuality when associated with ID.

KEYWORDS: Special Education. Intellectual Disability. Sexuality. Sexual Education.

\section{InTRODUÇÃo}

É pertinente entender e problematizar a interferência das várias concepções sociais e familiares no desenvolvimento e expressão da sexualidade de adolescentes com deficiência intelectual (DI), levando-se em consideração que eles possuem necessidades, impulsos e desejos, além de emoções normais, e, assim, também vivenciam e manifestam questões de natureza sexual como quaisquer outros jovens (BASTOS; DESLANDES, 2005; MAIA; CAMOSSA, 2003; GLAT, 1992).

O Estatuto da Criança e do Adolescente (BRASIL, 1990) circunscreve a adolescência como o período de vida que vai dos 12 aos 18 anos de idade. A adolescência marca a transição da infância para a idade adulta, sendo uma etapa muito importante do desenvolvimento humano, tendo em vista que nela ocorrem mudanças físicas relativas à puberdade, mudanças psicológicas referentes à formação da identidade e mudanças sociais associadas ao estabelecimento de vínculos grupais, ao início da vida sexual e a alguns remanejamentos nas relações familiares (TRINDADE; ANDRADE, 2005).

Pode-se referir à adolescência como uma fase típica do desenvolvimento dos jovens da nossa sociedade industrializada, que exige uma longa preparação de seus membros para a entrada no mundo adulto (BOCK; FURTADO; TEIXEIRA, 2007). Nesta fase emergem questões referentes à sexualidade, considerada como as diversas maneiras que as pessoas buscam para obter ou expressar prazer. Ainda, a adolescência é marcada por um período de frequentes alterações físicas, comportamentais e sentimentais, no qual se espera a transição da infância para a idade adulta. Este momento geralmente é conturbado para muitos indivíduos e poderá o ser ainda mais para adolescentes com deficiência intelectual (SCHWARTZMAN, 1999; DENARI, 1997; GLAT; FREITAS, 1996; GLAT, 1992).

É característica da deficiência intelectual (DI) um processo mental significativamente inferior à média, acompanhado de limitações no funcionamento adaptativo em pelo menos duas das seguintes áreas: comunicação, autocuidado, vida doméstica, habilidades sociais e interpessoais, uso de recursos comunitários, autossuficiência, habilidades acadêmicas, trabalho, lazer, saúde, segurança, entre outros (ASSUMPÇÃO JÚNIOR; SPROVIERI, 1993). 
Assim, as pessoas com deficiência intelectual não apresentam o desempenho esperado de acordo com sua idade, sexo e condição social, pois possuem um desenvolvimento cognitivo abaixo da média geral e, em geral, as circunstâncias sociais não favorecem a independência dos indivíduos com tal deficiência (SCHWARTZMAN, 1999; DENARI, 1997; GLAT; FREITAS, 1996; GLAT, 1992). Entretanto, a grande maioria das pessoas com deficiência intelectual apresenta comprometimento leve, sendo capaz, portanto, de desenvolver algum grau de autonomia, independência e assumir responsabilidades, como as de autocuidado (COLL; MARCHESI; PALACIOS, 2004; GLAT, 1992).

A alteração do desenvolvimento cognitivo é objetivamente comprovada e não vai mudar, o que pode ser alterado, portanto, é a atribuição social feita à deficiência intelectual (COLL; MARCHESI; PALACIOS, 2004; FRANÇA RIBEIRO, 1995). Assim, pode-se afirmar que as limitações impostas pela deficiência intelectual estão mais nas relações, na forma como o grupo social se relaciona com os indivíduos com deficiência intelectual e na maneira como eles mesmos se relacionam a partir da sua deficiência. Portanto, as dificuldades dessas pessoas advêm muitas vezes de suas relações sociais e não da deficiência intelectual em si (MAIA; CAMOSSA, 2003; DENARI, 1997; GLAT; FREITAS, 1996; GLAT, 1992).

Observa-se, que sexualidade é compreendida de forma mais ampla, abarcando o indivíduo em suas várias extensões (biológica, psicológica, social e cultural). Devendo assim, ser respeitada como um direito inerente a todos os indivíduos e vivenciada conforme a individualidade de cada um (MAIA; CAMOSSA, 2003).

A partir da última década, com as mudanças na concepção geral sobre a sexualidade e a criação de organizações sociais voltadas para a inclusão de pessoas com deficiência intelectual, houve significativas alterações na visão sobre elas, deixando-se de focar exclusivamente na deficiência intelectual e passando a considerá-la em sua totalidade, como indivíduos que possuem desejos e necessidades como todas as demais pessoas (GLAT; FREITAS, 1996).

\subsection{CONCEPÇÕES GERAIS SOBRE A SEXUALIDADE DE PESSOAS COM DEFICIÊNCIA INTE- LECTUAL}

Grande parte dos trabalhos publicados sobre sexualidade e deficiência intelectual são reflexões acerca do tema (BASTOS; DESLANDES, 2005; BLACHER, 2001; DENARI, 1997; GLAT; FREITAS, 1996; FRANÇA RIBEIRO, 1995) dentre outros, apesar de haver aumentado o número de pesquisas realizadas a fim de investigar a sexualidade em pessoas com deficiência intelectual (EASTGATE et al., 2011; MAIA; CAMOSSA, 2003).

No geral, os autores concordam que existem vários mitos baseados em concepções bastante difundidas de que todos os comportamentos e atitudes das pessoas com deficiência intelectual, incluindo a sexualidade, são considerados 
potencialmente anormais (MAIA; CAMOSSA, 2003; GLAT, 1992). Logo, nessa perspectiva sua sexualidade é tida como problemática ou patológica por natureza (MAIA, 2001; GIAMI, 2000). Um exemplo disso está na concepção de que os indivíduos com deficiência intelectual não têm condições de controlar seus impulsos sexuais e precisam ser medicados.

Ainda é comum a crença de que as pessoas com DI são assexuadas, quando não são vistas de forma infantilizada, como "eternas crianças e angelicais", ou, ao contrário, muitos acreditam que esses indivíduos são hipersexuados, com manifestação de aberrações e de uma sexualidade agressiva e animalesca (MAIA; CAMOSSA, 2003; GIAMI, 2000; GLAT; FREITAS, 1996). Tais concepções são oriundas da ausência da construção do papel sexual dos indivíduos com deficiência intelectual ao longo de seu desenvolvimento, o que se dá pela privação do convívio social, pela carência e deturpação das informações recebidas, bem como, pela não aceitação social de seus desejos, necessidades e capacidades sexuais (MAIA; CAMOSSA, 2003).

Também se faz presente na sociedade a concepção de que tais pessoas são deficientes ou retardadas em seu desenvolvimento sexual e afetivo, que possuem também uma deficiência emocional, e logo, são consideradas incapazes de estabelecer relações amorosas profundas e duradouras. Por serem rotulados como deficientes esses indivíduos com DI ficam, na prática, e algumas vezes juridicamente, também impedidos de casar, ter filhos ou levar uma vida sexual normal (GLAT; FREITAS, 1996).

Observa-se que comportamentos afetivo-sexuais, desde abraços, beijos e palavras até a masturbação e a relação sexual, que são encarados normalmente pela sociedade, se manifestados por pessoas com deficiência intelectual, passam a ser vistas de maneira preconceituosa e desviante, tornando-se intoleráveis e aberrantes (MAIA, 2001; GIAMI, 2000).

Diversos estudos têm levado em consideração alguns fatores que limitam a vivência da sexualidade nas pessoas com deficiência intelectual, classificados em fatores físicos como restrição física e ausência de locomoção; fatores psicológicos como depressão, insegurança e baixa autoestima e, ainda, fatores sociais como isolamento e discriminação social (MAIA; CAMOSSA, 2003; DENARI, 1997; GLAT; FREITAS, 1996; FRANÇA RIBEIRO, 1995; GLAT, 1992).

A maneira infantilizada e discriminatória como são tratadas pela sociedade e a pequena expectativa em relação às suas possibilidades de crescimento e realização estão presentes também no âmbito familiar, influenciando as percepções e as atitudes das mães com seus filhos que apresentam deficiência intelectual (GLAT; FREITAS, 1996; GOFFMAN, 1988). A influência familiar é determinante no processo de integração social dos indivíduos com DI, podendo atuar de maneira facilitadora ou impeditiva, pois, segundo Glat e Freitas (1996):

[...] essa arrumação familiar em função do indivíduo com necessidades especiais é fruto de um sentimento legítimo de proteção e defesa desse membro mais frágil no enfrentamento das dificuldades cotidianas entre as quais se incluem a discriminação e a rejeição social (p.20). 
Assim, o grau de socialização que os referidos indivíduos apresentarão será consoante com o investimento que a família empregará na constituição de sua autonomia e identidade, podendo definir o quão satisfatório será seu desenvolvimento psicossocial e sexual. Muitos jovens com deficiência intelectual possuem características físicas de jovens normais, porém não estão preparados para demandas da vida independente (GLAT; FREITAS, 1996; FRANÇA RIBEIRO, 1995).

Dessa forma, a expectativa das mães com relação à liberdade de seus filhos é diferente, fazendo com que dificilmente elas contribuam para desenvolverem neles o sentido de independência e responsabilidade. Isso pode ser observado a partir de atitudes preconceituosas disfarçadas, como: não dar voz a esse adolescente e não considerar a sua vontade (SCHWARTZMAN, 1999). Ressalta-se que falar sobre a sexualidade dos adolescentes em família é indispensável nessa fase de constantes transformações e isso não pode ser diferente quando se tratam de adolescentes com deficiência intelectual.

Segundo Pinel (1999) a falta de informações relacionadas à educação sexual pode levar a problemas de interação social e de construção de uma identidade social, o que pode repercutir em entraves emocionais e carências afetivas que, por sua vez, estimulam o desenvolvimento de uma autoimagem distorcida, além de crenças e de expectativas falsas.

Muitas mães encaram seus filhos com deficiência intelectual como sexualmente infantis, afirmando a ideia de que apenas os adultos economicamente independentes têm direito a uma vida sexualmente ativa (THARINGER; HORTON; MILLEA, 1990). Assim, algumas dessas mães reconhecem as curiosidades e os impulsos sexuais de seus filhos com DI, porém, sua preocupação se foca em encontrar meios de controlar e canalizar as manifestações dessa sexualidade (GLAT; FREITAS, 1996).

Além disso, por muitas vezes ignorarem a sexualidade de seus filhos, as citadas mães não prestam nenhum tipo de educação a respeito e ainda se surpreendem quando os pegam sexualmente excitados, atribuindo este comportamento inapropriado à sua deficiência intelectual, o que tem se mostrado como um dos maiores problemas relacionados ao tema no caso desses indivíduos, segundo revisão realizada por Conod e Servais (2008).

Percebe-se ainda que as condutas dessas mães baseiam-se em proibições e repressões sem nenhuma explicação e em alguns casos essa coação é tanta que elas permitem esterilizar seus filhos com deficiência intelectual, ainda jovens, e na maioria das vezes, sem o seu consentimento ou conhecimento, levando-os a perder toda uma vida de procriação no futuro. Associada a todos esses fatores, a superproteção das mães faz com que seus filhos tenham poucas oportunidades de se relacionar livremente (MAIA, 2001; FRANÇA RIBEIRO, 1995; GLAT; FREITAS, 1996; GLAT, 1992).

Érelevanteainda salientar que principalmente a infantilizaçãoe isolamento social os impedem de gozar de uma vida amorosa plena e satisfatória, resultando 
numa terrível solidão ao atingir a vida adulta (GLAT; FREITAS, 1996). Para isso, mostra-se igualmente indispensável por parte dessas mães o conhecimento acerca das características da adolescência, das particularidades dessa etapa da vida e, principalmente, de como a deficiência intelectual pode influenciar o processo de amadurecimento integral dos indivíduos.

No Brasil, são ainda escassos os estudos realizados que buscam investigar temas relacionados à sexualidade das pessoas com deficiência intelectual (CAVALCANTI, 1993), bem como, para analisar as concepções de mães sobre a sexualidade de seus filhos com DI. Nesse sentido, pretendeu-se pesquisar as percepções que as mães de jovens com deficiência intelectual têm sobre a sexualidade de seus filhos, e, como tais concepções podem estar relacionadas à adoção ou não de uma prática de educação sexual voltada para esses indivíduos.

\section{Método}

\subsection{Participantes}

A população abordada na presente pesquisa foi composta por 20 mães (denominadas M1, M2, M3, M4, M5, [...] M20) que possuíam filhos adolescentes com idade entre 12 a 18 anos, de ambos os sexos, com indicação de diagnóstico de deficiência intelectual, atendidos numa clínica escola de uma instituição de ensino superior do estado do Espírito Santo.

Nesse sentido, na realização dessa pesquisa exploratória e qualitativa (OLIVEIRA, 1999), utilizaram-se como critérios de exclusão os seguintes princípios: a) mães de indivíduos menores de 12 anos e maiores de 18 anos; b) mães de adolescentes que não estejam em tratamento na referida clínica escola; c) mães de adolescentes sem indicação de diagnóstico de deficiência intelectual.

A pesquisa foi aprovada pelo Comitê de Ética em Pesquisa da instituição de ensino superior. As participações por meio de entrevistas às mães de jovens com deficiência intelectual foram de caráter voluntário, assinando o Termo de Consentimento Livre e Esclarecido contendo informações explicativas sobre a pesquisa, e foram realizadas nas salas reservadas de atendimento ao público na própria clínica escola, em datas previamente agendadas com a Coordenação do curso de Psicologia. Assim tais participações estiveram embasadas em princípios éticos das pesquisas científicas em seres humanos, previstos na Resolução $\mathrm{n}^{\circ}$ 196/96 (MINISTÉRIO DA SAÚDE, 1996).

\subsection{INSTRUMENTOS E PROCEDIMENTOS}

Inicialmente foi realizado o contato com a Coordenadora da clínica escola, na obtenção da devida autorização como órgão competente para o início da pesquisa. Posteriormente verificou-se com os profissionais da instituição de ensino superior a existência da população requerida, para que se contactasse e agendasse as entrevistas com as mães de adolescentes com diagnóstico de deficiência 
intelectual. O período de coleta de dados transcorreu entre os meses de setembro a dezembro de 2010.

A execução da pesquisa situou-se no âmbito de uma metodologia qualitativa, que permitiu investigar com maior profundidade o tema em questão. Para isso, foi elaborado e aplicado um roteiro de entrevista semiestruturado com seis questões abertas visando analisar as percepções das mães sobre as manifestações sexuais de seus filhos adolescentes com deficiência intelectual e que serviram de eixos norteadores da discussão que segue. Sendo as seguintes perguntas:

1. O que você entende por sexualidade?

2. Você acha que seu filho tem sexualidade? Por quê?

3. Você observa no seu filho comportamentos que indiquem interesse em relacionar-se sexualmente com alguém? Se sim, quais seriam?

4. Você permitiria ou já permitiu que seu filho tivesse um relacionamento afetivo e sexual? Por quê?

5. Você acha que a pessoa que tem um atraso cognitivo (deficiência intelectual) tem uma sexualidade diferente ou igual às demais pessoas? Por quê? Explique.

6. Você já orientou seu filho sobre alguma questão ou atitude que deveria adotar sobre as manifestações de sua sexualidade? Se sim, qual seria?

As sessões das entrevistas foram individuais e reservadas, tendo duração média de 20 minutos e os dados coletados foram gravados e transcritos literalmente, preservando a qualidade e a precisão das informações prestadas.

\subsection{AnÁlise de dAdos}

Após a transcrição das entrevistas, os dados qualitativos obtidos foram apreciados de acordo com o método de Análise de Conteúdo formulado por Bardin (1977). Conforme esse procedimento as informações foram sintetizadas seguindo os seguintes eixos temáticos:

(a) percepções das mães sobre a sexualidade de seus filhos adolescentes com diagnóstico de deficiência intelectual;

(b) implicações das concepções das mães nas manifestações da sexualidade de seus filhos com DI quanto à construção de suas identidades social e sexual;

(c) existência de alguma educação sexual na orientação aos filhos com deficiência intelectual.

A análise de dados também foi realizada conforme os conteúdos presentes nos relatos das participantes, que se relacionaram $\mathrm{m}$ com os objetivos específicos da referida pesquisa. 


\section{Resultados e discussões}

A investigação foi pautada pela apreensão das percepções das mães sobre a sexualidade de seus filhos adolescentes com deficiência intelectual. A partir dos dados coletados, evidenciou-se uma grande dificuldade das participantes em abordar especificamente o tema da sexualidade, na medida em que suas respostas foram bastante difusas, necessitando que as questões norteadoras fossem reformuladas várias vezes para que assim as mesmas pudessem respondê-las.

Assim, quanto à categoria (a) percepções das mães sobre a sexualidade de seus filhos adolescentes com diagnóstico de deficiência intelectual, dentre as mães entrevistadas, houve um número bastante significativo de conceituações, no total de 12 respostas, a respeito da ausência de sexualidade na pessoa com deficiência intelectual, apresentando tanto uma postura de infantilização quanto de superproteção dessas mães em relação a seus filhos, tal como já apontado por autores como Maia (2001); França Ribeiro (1995); Glat e Freitas (1996); Glat (1992), dentre outros. Os relatos verbais abaixo ilustram tais posturas:

Eu acho que não, ele é infantil, muito criança e apesar dele achar que é adolescente, o comportamento dele é de criança (M3);

Não tem sexualidade, ele não se importa com isso, só quer brincar de carrinho o dia inteiro. Nunca vi ele fazer nada, nem se insinuar (M5);

Não, ela é inocente, tem a mentalidade bem atrasada, é diferente, então pra ela tanto faz como tanto fez ter sexualidade (M9);

Não tem por conta da deficiência dele, pelas dificuldades, é sempre quieto (M12).

Observou-se ainda em alguns discursos o quanto as percepções de tais mães estavam marcadas pela visão de que seus filhos, em função da deficiência intelectual, são "eternas crianças" (GIAMI, 2000; GLAT; FREITAS, 1996), com pouca ou nenhuma possibilidade de crescimento pessoal e muito menos de desenvolvimento de interesses e comportamentos de cunho sexual:

Vejo ela como uma criança, não tem muita noção, ela não leva nada a sério, pois sua idade é metade de uma criança normal (M2);

Não, ela não tem sexualidade porque tem todo um jeito de criança, não tem noção de nada, o sentimento dela é outra coisa, pois ela, coitada, é diferente, não entende e não sente nada (M14);

Você vendo ele assim é tranquilo a parte do homem né, tem certa inocência de criança entendeu. A parte de criança ainda é muito grande nele (M18).

Ao tecer considerações sobre este sentimento de superproteção maternal não se deve deixar de salientar que a estrutura familiar das pessoas com deficiência intelectual acaba por se formar em torno desses indivíduos, considerados em função de sua necessidade especial, diferentes e mais frágeis, e que tudo o que é referente a eles é minimizado ou desconsiderado, incluindo-se aí sua sexualidade (MAIA, 
2001; FRANÇA RIBEIRO, 1995; GLAT; FREITAS, 1996; GLAT, 1992). Observa-se que a dedicação das mães aos cuidados com seus filhos com DI confere a elas uma noção de total dependência desses adolescentes, como se fossem sempre infantis.

Em função das preocupações e dificuldades cotidianas, aliadas à incerteza sobre a autonomia de seus filhos, muitas mães desenvolvem uma postura de excesso de proteção em relação a eles, limitando suas possibilidades de desenvolvimento, entre elas, a sexual, além de gerar carências, inseguranças, frustrações e incompreensões (MAIA; CAMOSSA, 2003; DENARI, 1997; GLAT; FREITAS, 1996; FRANÇA RIBEIRO, 1995; GLAT, 1992).

Essa atitude exclusivista promove limitações e comprometimentos nas habilidades de relacionamento e interação do jovem com DI com outras pessoas, podendo gerar dificuldades em se separar de seus familiares, de fazer amigos e até mesmo, em se envolver afetivo-sexualmente com os demais (BASTOS; DESLANDES, 2005; GLAT, 1992).

As mães de filhos com deficiência intelectual inevitavelmente se perguntaram se no futuro haverá algum momento em que seus filhos adquirirão uma maturidade que os permitam ser independentes e, em muitos casos, as citadas mães se viram obrigadas a estender os cuidados com seus filhos para além da infância, convivendo com eles até a idade adulta (COLL; MARCHESI; PALACIOS, 2004). Essa relação de dependência prolongada contribui para a construção da falsa noção de imaturidade e irresponsabilidade da pessoa com deficiência intelectual, o que ficou bem evidente nos discursos das entrevistadas.

Quanto às mães que afirmaram que seus filhos possuíam alguma sexualidade, a consideraram de maneira biológica e naturalizante, segundo os relatos verbais abaixo:

Tem, eu acho que todos nós seres humanos temos, pelo instinto de estar vivo (M1);

Não sei, tem né, sei lá, eu acho que todo mundo tem, aí eu acho que ele tem (M4);

Tem sexualidade porque ela já se formou, deve sentir coisas que é normal sentir, mas eu acho que é só (M7);

Ah, eu acredito que sim porque ele é uma pessoa que olha, anda, fala, ele tá vivo, ele vive né, eu acho que como ele vive, ele tem sim (M13).

Ao investigar a categoria (b) referente às implicações das concepções das mães nas manifestações da sexualidade de seus filhos com DI quanto à construção de suas identidades social e sexual observou-se que a maior parte das participantes, no total de 15 mães, disse que não permitiria que seus filhos com DI se relacionassem afetivamente e sexualmente, no presente ou no futuro, com outras pessoas, alegando que eles não vivenciavam as mesmas questões sobre a sexualidade que outras pessoas da mesma idade, apresentando também uma ausência de interesse por experiências como a de namoro. 
Assim, tais dados descritos refletiram o entendimento de que a sexualidade de pessoas com deficiência intelectual é para elas diferente da de pessoas sem qualquer deficiência, como corroboram os exemplos seguintes:

É diferente porque ele não pensa igual uma pessoa normal (M13);

Acho que é diferente porque eu acho que eles têm mais hormônios, ficam mais atacados do que o normal (M15);

Na verdade a sexualidade neles aflora mais cedo, por isso é diferente, eu acho que o remédio ajuda um pouco porque estimula a parte cerebral neles e na medida que estimula a parte cerebral de aprendizagem também estimula a parte sexual, fica bem mais aflorada, elas se formam mais cedo, criam corpo mais cedo, elas ficam interessadas no sexo mais cedo do que o normal (M17).

\section{Foram observados outros relatos que evidenciaram essa mesma concepção apontada anteriormente:}

Acho que é diferente, mais aflorada, porque eles têm um pouco menos de controle do que de uma pessoa dita normal (M1);

É diferente por ele não ter apresentado nada até agora, acho então que é tranquilo e que até tá meio bloqueada um pouco (M3);

Se ela fosse uma pessoa, vamos supor: normal, ela não tava mais quieta dentro de casa, não era sossegada assim, já teria saído de casa (M9);

A sexualidade dele é diferente porque não chegou nessa faixa ainda por causa do corpo dele, ele está atrasado em relação às outras crianças (M11);

Ele é mais tranquilo entendeu, em outras crianças a gente sente aquilo mais aflorado, é mais visível, o dele já é mais tranquilo, eu não sei se é pelo motivo dele não saber o que pode e o que não pode (M12).

Nesse sentido, seis participantes entrevistadas relataram ser impossível que seus filhos com deficiência intelectual pudessem se relacionar com alguém, embasadas em suas limitações e falta de autonomia, refletindo tais concepções numa educação repressora, proibitiva e/ou omissa (MAIA; CAMOSSA, 2003). As citadas posturas podem ser facilmente identificadas nas seguintes afirmações:

Não. Porque não. Deus me livre. Tem mente pra isso não (M5);

Jamais, eu não acho que ela está preparada, e não sei se algum dia ela vai estar, eu acho que ela não vai estar, porque a idade mental dela é muito menor do que a idade do corpo, esses desejos e essas vontades que ela tem é do corpo dela. Eu acho que para ter um relacionamento a pessoa tem que ter responsabilidade e eu não acho que esse vai ser o caso dela tão cedo (M6);

Não, porque é complicado, eu penso em proteger a minha filha porque ela não tem noção, acho que ela não precisa de namorar, porque na 'cabeçinha' dela não passa nada nesse sentido (M19). 
Diante dos ilustrados discursos verbais das mães, pode-se inferir que o desenvolvimento sexual dos jovens com deficiência intelectual encontra-se comprometido, pois, na maioria das respostas apresentadas, ficou evidente que seus filhos com DI crescem segregados de qualquer convívio social, principalmente em relação ao contato com o sexo oposto. Neste caso, a construção das identidades social e sexual desses jovens é bastante prejudicada, influenciando, sobretudo na capacidade de manifestação de seu papel social e sexual (MAIA; CAMOSSA, 2003; MAIA, 2001; GLAT; FREITAS, 1996).

As barreiras sociais e sexuais podem vir em forma de isolamento, segregação, repressão e/ou discriminação, e com elas ocasionar dificuldades de socialização, carência afetiva, depressão, bloqueio emocional, além de sentimentos de inferioridade, frustração e baixa autoestima, entre os jovens com deficiência intelectual (MAIA; CAMOSSA, 2003; DENARI, 1997; GLAT; FREITAS, 1996; FRANÇA RIBEIRO, 1995; GLAT, 1992; GOFFMAN, 1988).

A partir das assertivas abaixo citadas, é notável perceber que as relações interpessoais incluindo as sexuais, são intoleradas e consideradas como problemáticas se relacionadas às limitações e incapacidades de cunho intelectual dos indivíduos com DI, considerando aqui os comportamentos sexuais manifestados desde os mais simples, como abraçar, beijar, falar palavras íntimas, até os mais complexos, como masturbar, praticar a relação sexual em si, namorar ou casar (GLAT; FREITAS, 1996; FRANÇA RIBEIRO, 1995; ASSUMPÇÃO JÚNIOR; SPROVIERI, 1993):

Eu não deixo ela sair de casa, nem conversar com os outros, e muito menos namorar, porque a mente dela não é certa. O médico disse que ela tem a mente de uma criança de cinco anos. Então eu acho que nem tudo o que os outros fazem, ela pode fazer também (M9);

No momento eu não deixo nem ele chegar perto de uma menina, se ele fosse mais velho a gente até aceita né, abraçar e beijar, mas eu não acho certo agora isto também não. Eu fico preocupada porque ele não tem juízo, vai que engravida alguém (M10);

Não deixo não, porque não acho certo, ela não tem noção se está namorando, se está beijando, pra mim ela não tem noção dessas coisas, é fazer por fazer, pra mim ela é assim como se fosse um bebê, então por isso eu acho que não é certo ela namorar, e casar nem pensar (M14).

Sendo assim, comportamentos antes tolerados nos indivíduos "ditos normais" ou "não deficientes" tornam-se problemáticos e carregados de conotações preconceituosas e desviantes nos indivíduos com deficiência intelectual, o que reforça ainda mais a discriminação dos mesmos (GIAMI, 2000; GOFFMAN, 1988).

Silva e Dessen (2001) e Montanari (1999) argumentam sobre o preconceito e a discriminação a que são enfrentados os adolescentes com deficiência intelectual, e explicam que a própria deficiência é em si vista como um sinal de "inferioridade" 
e de "negatividade" por estar embutida a ideia de "diferença" entre os indivíduos. E acrescentam que é exatamente este entendimento que reforça na sociedade a concepção de que os jovens com DI estão sempre numa situação de "desvantagem" em comparação aos demais indivíduos.

Da mesma forma como tais autores afirmaram, no relato das mães entrevistadas ficou evidente que muitas delas evitam o confronto direito com o preconceito, e, por vezes, limitam as atividades interpessoais de seus filhos com DI e não permitam que eles desfrutem de qualquer vivência afetivo-sexual.

Destacam-se ainda determinadas falas em que foi percebida uma certa dúvida entre a permissão ou não do namoro, uma vez que algumas mães afirmaram nem sequer terem pensado sobre a possibilidade de seus filhos desejarem se relacionar sexualmente com outras pessoas:

Eu nunca pensei nisso não, mas não acho ruim namorar, é só não dar margem assim para uma coisa mais séria. Se um dia ele quiser transar e casar, aí é um caso a se pensar, pra mim ficou um pouco mais difícil, eu penso assim que por enquanto ele ainda não descobriu isso, mas quando descobrir eu tenho medo dele não saber lidar com isso, e não saber se controlar, meu medo é esse (M8);

Acho difícil deixar namorar, nem sei, porque a gente vê ele como criança mesmo e não vê como adulto, daí fica difícil a resposta (M18);

Eu acho que se um dia ele quiser namorar eu vou ter sérios problemas, porque eu tenho medo. Nem sei explicar direito, é tanta coisa que passa na minha cabeça. $\mathrm{O}$ pai fala que quando ele tiver mais idade, vai levar ele para namorar, eu disse que não, que é pra deixar ele quietinho. Eu brinco que se ele quiser arrumar uma namorada, aí sim, eu vou pensar muito (M20).

Outro dado interessante é que, segundo as entrevistadas, nenhum dos filhos adolescentes com DI havia manifestado qualquer vivência afetivo-sexual, o que provavelmente seria considerado incomum para adolescentes com a mesma faixa etária e com condição intelectual preservada. Isso levanta o questionamento sobre estar novamente diante de concepções que subestimam as necessidades, os desejos e as capacidades sexuais desses jovens de se relacionarem afetivamente; ou de realmente tratar-se de um atraso na manifestação de interesses dessa ordem, já que a demora na apresentação de comportamentos relacionados à sexualidade, como o interesse pelo namoro, pode ser entendido a partir da dificuldade que as pessoas com DI têm em articular ações relacionando os meios com os fins para obter algum resultado (COLL; MARCHESI; PALACIOS, 2004).

E em relação à categoria (c) existência de alguma educação sexual na orientação aos filhos com deficiência intelectual percebeu-se que a maioria das participantes, no total de 12 mães, diz nunca ter orientado sexualmente seus filhos, alegando que estes não iriam compreender, tal como mostram os relatos verbais na sequência:

Não, nunca falei nada porque ela é muito sossegada (M2); 
Não, nunca conversei com ele não (M5);

Eu nunca conversei porque não adianta conversar com ela, ela é diferente, sabe? Ela não entende, você pode falar só que ela não vai saber o que é que é isso (M7);

Não oriento porque ela não entende, mas se ela entendesse com certeza eu explicaria (M9);

Não, porque ele não entenderia se eu chegar pra ele e conversar coisas que ele não entenderia, pra mim não adiantaria, porque não vai entrar na cabeça dele (M10);

Não, eu não sei explicar isso para ele, ele não vai ouvir (M12);

Não, ainda não conversei porque não vi a necessidade de falar sobre isso (M14);

É difícil conversar, pois ele não entende nada e não tem noção das coisas (M18).

Com relação à existência de alguma forma de educação sexual para com esses adolescentes com DI, observou-se uma dificuldade acentuada dessas mães no processo de se educar sexualmente, marcada, às vezes, por uma notável ausência do mesmo (KONSTANTAREAS; LUNSKY 1997). Tal fato revela o que tem se mostrado um dos maiores problemas no caso de pessoas com deficiência intelectual, de acordo com a revisão realizada por Conod e Servais (2008). Essa negligência acaba por produzir uma vulnerabilidade na constituição da identidade social, bem como sexual desses jovens, podendo comprometer seu desenvolvimento emocional e afetivo (MAIA, 2001; PINEL, 1999).

No geral, foi possível perceber que as mães não reconhecem uma identidade sexual em seus filhos e, por conseguinte, não fornecem qualquer tipo de educação de caráter sexual, reproduzindo a concepção social vigente em nossa cultura que nega a existência da sexualidade quando associada à deficiência intelectual. Conforme Maia e Camossa (2003):

[...] acredita-se que as pessoas com deficiência mental, em geral, passam a vida recebendo uma educação sexual familiar permeada de mitos e preconceitos sem disporem de uma orientação formalizada, pertinente, que permitiria extrapolar a repressão e a negação de sua sexualidade (p.207).

Já a minoria das entrevistadas, no total de oito mães, que afirmou fazê-lo, relatou informações acerca de comportamentos em público e orientações quanto a comportamentos defensivos de qualquer violação sexual, enfocando sempre uma regra proibitiva, tal como ilustrado nas afirmativas a seguir:

Eu já falei pra ele que não pode sair pelado por aí, que não pode fazer isso, que só pode tirar a roupa dentro do banheiro, não pode ficar dentro de casa sem roupa, que tem que fechar a janela para tirar a roupa ou vestir (M11);

Eu nunca conversei com ele a respeito de nada disso nesta parte sexual, só orientei, como se comportar na rua, não chegar perto de pessoas do sexo oposto, mas sobre sexo, nunca conversamos, pois não percebi interesse dele em saber (M13). 
Seguem as demais falas que destacam ainda tal posicionamento das participantes:

Já falei quando o menino chegar perto dela ou chamar, pra ela não ir, pra ela chegar perto de ninguém de jeito nenhum (M6);

Já falei algumas coisas que não se pode fazer: igual olhar as meninas, passar a mão nelas, beijar na boca, porque isso ele via os outros fazerem (M8);

Teve uma época que ele começou a mexer muito no órgão genital, aí eu falei com ele que não pode, pra não ficar fazendo isso assim (M16);

Já falei que quando entrar no banheiro, se algum menino for atrás dela, não permitir que ponha a mão em canto nenhum dela, que é para chamar logo um adulto, e que não tenha vergonha de falar disso (M19).

Nesse sentido, percebeu-se que as percepções desse grupo revelaram uma atitude salutar das mães com relação ao enfrentamento da realidade inevitável do afloramento sexual de seus filhos deficientes. Afinal, é consenso entre estudiosos do tema (EASTGATE et al., 2011; CONOD; SERVAIS, 2008; BASTOS; DESLANDES, 2005; BLACHER, 2001) que educar sexualmente uma pessoa com deficiência intelectual, como no caso de qualquer outra pessoa sem tal deficiência, deve envolver atitudes maternas dirigidas à busca de uma maior autonomia para seus filhos, através do desenvolvimento de suas habilidades e competências com maior independência.

A educação sexual compreende diversos aspectos da sexualidade e das relações que a pessoa estabelece consigo mesma e com as demais. Assim, deve-se orientar o indivíduo com informações sobre a própria higiene pessoal, as mudanças físicas típicas da puberdade, a exploração da curiosidade sexual pela prática masturbatória, os nomes e as funções das partes genitais do corpo, os métodos contraceptivos, os cuidados referentes ao abuso sexual, abrangendo ainda assuntos como namoro, casamento, nascimento, as diferenças entre os papéis sexuais, entre outros (BASTOS; DESLANDES, 2005; MAIA, 2001; FRÓES, 2000; BUSCAGLIA, 1997; VITIELLO, 1995; THARINGER; HORTON; MILLEA, 1990).

Entretanto, percebeu-se que a referida minoria das mães que apresentou alguma preocupação com relação à educação sexual de seus filhos com DI não vai além de ofertar informações sobre normas de convivência em público, comportamentos com relação ao sexo oposto, indicando ainda uma preocupação muito maior em evitar o contato mais íntimo com outras pessoas, principalmente para resguardar a ocorrência de qualquer tipo de violência sexual. Fato esse que revela a existência de preconceitos por parte também dessas mães.

Outro aspecto interessante percebido nos discursos dessas mães é a concepção de que conversar sobre a sexualidade pode despertar um interesse que ainda encontra-se "adormecido", corroborando autores como Konstantareas e Lunsky (1997). Para esses autores, mesmo diante de circunstâncias cotidianas que 
apresentam as manifestações da sexualidade, muitos familiares não conseguem aceitar ou enfrentar tais situações e geralmente acabam por ignorá-las, devido a dificuldades encontradas por eles mesmos em lidarem com o assunto ou por acreditarem que conversar sobre a sexualidade com seus filhos pode funcionar como um estímulo para o seu surgimento:

Eu não vi necessidade de falar porque tenho medo de ao invés de ajudar, atrapalhar e incentivar, pois não vejo ele como adulto para falar sobre isso (M15);

Não, não conversei nada, deixa quieto, ela não é certa mesmo, e se ela quiser se juntar com uma pessoa por causa disso que eu for falar, e não der certo? (M17).

Observou-se que por temor de que uma simples conversa de cunho sexual desperte comportamentos até então ausentes acaba justificando a total ausência de educação com relação ao desenvolvimento sexual desses indivíduos, corroborando os resultados da pesquisa recentemente realizada por Eastgate et al. (2011). Por consequência, é possível que a maneira infantilizante e discriminatória de adolescentes com deficiência intelectual serem tratados pela sociedade influencia as percepções de suas mães sobre eles, influenciando, assim, a maneira como lidam e manifestam sua sexualidade (GOFFMAN, 1988).

Sendo os valores e as concepções da família importantes para a constituição dos indivíduos, pode-se entender que as mudanças nas concepções e atitudes limitantes dessas mães perante as manifestações da sexualidade de seus filhos contribuirão para que elas possam ser vivenciadas de maneira mais saudável. Isso acontece porque a influência familiar é de extrema importância para o processo de interação dos indivíduos com deficiência intelectual, já que é através dela que eles desenvolvem seus valores, suas percepções de mundo, a construção de sua identidade e também de sua sexualidade (COLL; MARCHESI; PALACIOS, 2004).

Tais dados reforçam a concepção debatida e defendida por muitos estudiosos da área, como Maia (2001); Fróes (2000); Buscaglia (1997); Glat e Freitas (1996), e Vitiello (1995) de que é importante a proposta de programas de educação sexual que sejam colocados em prática junto à população de pessoas com deficiência intelectual, dirigidos tanto aos jovens como às suas mães, de forma que as mesmas possam oferecer informações básicas para educarem sexualmente seus filhos. Dessa forma, acredita-se que somente assim, se pensará em uma sociedade em que o tema "sexualidade e deficiência intelectual" possa ser compreendido como algo natural, independente da condição mental das pessoas envolvidas.

\section{CONSIDERAÇÕES FINAIS}

Apesar da importância de se considerar a sexualidade de pessoas com deficiência intelectual, percebe-se o quanto este tema ainda está revestido de preconceitos, mistificações e discriminações, principalmente no contexto da família (GIAMI, 2000; GOFFMAN, 1988). A questão da sexualidade, em suma, 
não pode ser entendida como um episódio isolado dos demais aspectos da vida de um indivíduo com deficiência intelectual, uma vez que, a sexualidade é inerente à condição humana (MAIA; CAMOSSA, 2003). Observou-se que a maior problemática que recai sobre a sexualidade das pessoas com DI, não se encontra somente nas limitações da própria "condição deficiente", mas sim, na desinformação, no preconceito, na negação e/ou na indiferença sobre o assunto (BASTOS; DESLANDES, 2005; GIAMI, 2000; DENARI, 1997; FRANÇA RIBEIRO, 1995).

Através das entrevistas realizadas, percebeu-se entre as mães posturas que vão desde a total negação da sexualidade de seus filhos com deficiência intelectual até aquelas que consideram melhor não lidar diretamente com a situação por receio de que seja exatamente isso que vá despertar o interesse sexual desses adolescentes (KONSTANTAREAS; LUNSKY 1997).

A postura assumida pelas mães, que na verdade reflete a dificuldade em compreender e aceitar a construção da identidade sexual de seus filhos acaba por impedir a adoção de comportamentos parentais voltados à educação sexual, o que favorece a manifestação de condutas infantilizadas e inadequadas destes jovens frente aos seus interesses sexuais (COLL; MARCHESI; PALACIOS, 2004; MAIA, 2001; GIAMI, 2000; DENARI, 1997; GLAT; FREITAS, 1996).

A partir da compreensão da deficiência intelectual como um rebaixamento que gera limitações no desenvolvimento da maturidade emocional e social, as mães mantêm seus filhos num status infantilizado, percebidos como "eternas crianças" (GIAMI, 2000; GLAT; FREITAS, 1996).

A vivência sexual dos jovens com deficiência intelectual, quando bem conduzida, melhora o desenvolvimento e o equilíbrio afetivo, incrementa a capacidade de estabelecer contatos interpessoais, fortalece a autoestima e contribui para a inclusão social. Conversar, orientar e construir no interior da família uma relação de confiança é primordial para ajudar esses jovens a lidar com sua sexualidade (BASTOS; DESLANDES, 2005; MAIA; CAMOSSA, 2003; MAIA, 2001).

Compreender a deficiência intelectual como um fenômeno socialmente construído e abordar a sexualidade como parte integrante, constitucional e formativa de todas as pessoas é o primeiro passo na direção de uma educação sexual adequada que, quando realizada, pode auxiliar as pessoas com deficiência intelectual a encontrarem formas saudáveis de satisfazer seus impulsos, além de diminuir radicalmente os riscos de abuso sexual, de comportamentos socialmente inadequados, de gravidez indesejada e da incidência de doenças sexualmente transmissíveis (MAIA; CAMOSSA, 2003; MAIA, 2001).

A demanda que fica, então, é que, se há uma discussão e implementação dessa questão sexual de forma mais reflexiva e respeitável possível no âmbito familiar, em especial entre as mães e seus filhos com DI, consequentemente permitirá que preconceitos e discriminações que envolvem esses indivíduos sejam 
revistos e que se assegurem os direitos de um exercício pleno, seguro e saudável de sua sexualidade.

\section{REFERÊNCIAS}

ASSUMPÇÃO JÚNIOR, F. B.; SPROVIERI, M. H. Deficiência mental, família e sexualidade. São Paulo: Memnon, 1993.

BARDIN, L. Análise de conteúdo. Lisboa: Edições 70, 1977.

BASTOS, O. M.; DESLANDES, S. F. Sexualidade e o adolescente com deficiência mental: uma revisão bibliográfica. Ciência E Saúde Coletiva, Rio de Janeiro, v.10, n.2, p.389-397, 2005.

BLACHER, J. Transition to adulthood: mental retardation,families and culture. American Journal on Mental Retardation, v.106, p.173-188, 2001.

BOCK, A. M. B.; FURTADO, O.; TEIXEIRA, M. L. T. Psicologias: uma introdução ao estudo de psicologia. 13. ed. São Paulo: Saraiva, 2007.

BRASIL. Lei n ${ }^{\circ}$ 8.069, de 13 de julho de 1990. Estatuto da Criança e do Adolescente. Dispõe sobre a proteção integral à criança e ao adolescente. Ministério da Educação, Brasília, 16 jul. 1990. Disponível em: <http:/ / portal.mec.gov.br/seesp/arquivos/pdf/ lei8069_02.pdf>. Acesso em: 10 jun. 2010.

BUSCAGLIA, L. Os deficientes e seus pais: um desafio ao aconselhamento. 3.ed. Rio de Janeiro: Interamericana, 1997.

CAVALCANTI, R. C. Educação Sexual no Brasil e na América Latina. Revista Brasileira de Sexualidade Humana. São Paulo, v.4, n.2, p.164-173, 1993.

COLL, C.; MARCHESI, A.; PALACIOS, J. Desenvolvimento psicológico e educação:

Transtornos de desenvolvimento e necessidades educativas especiais. 2. ed. Porto Alegre: Artmed, 2004. v.3.

CONOD, L.; SERVAIS, L. Sexual life in subjects with intellectual disability. Salud pública México, v. 50, suppl.2, p. s230-s238, 2008.

DENARI, F. O adolescente especial e a sexualidade: nem anjo, nem fera. 1997. Tese (Doutorado) - Universidade Federal de São Carlos, São Carlos, 1997.

EASTGATE, G. et al. Women with intellectual disabilities: a study of sexuality, sexual abuse and protection skills. Australian Family Physician, v.40, n.4, p.226-30, 2011.

FRANÇA RIBEIRO, H. C. Orientação sexual e deficiência mental: estudos acerca da implementação de uma programação. 1995. Tese (Doutorado) - Universidade de São Paulo, São Paulo, 1995.

FRÓES, M. A.V. Sexualidade e deficiência. Temas sobre desenvolvimento. São Paulo, v.8, n.48, p.24-29, 2000.

GIAMI, A. Stérilisation et sexualité des personnes handicapées mentales. In: GIAMI, A; LERIDO, H (Eds.). Les enjeux de la stérilisation. Questions en Santé Publique Inserm/ INED, Paris, 2000. p. 273-315, 
GLAT, R.; FREITAS, R. C.. Sexualidade e deficiência mental: pesquisando, refletindo e debatendo sobre o tema. In: GLAT, R; FREITAS, R. C. Questões atuais em Educação Especial, Rio de Janeiro: Sette Letras, 1996. v. 2.

GLAT, R. A sexualidade da pessoa com deficiência mental. Revista Brasileira de Educação Especial, São Carlos, v.1, n.1, p.65-74, 1992.

GOFFMAN, E. Estigma: notas sobre a manipulação da identidade deteriorada. Traduzido por Márcia Bandeira de Mello Leite. 4. ed. Rio de Janeiro: LTC, 1988.

KONSTANTAREAS, M.; LUNSKY, Y.J. Sociosexual knowledge, experience, attitudes, and interest of individuals with autistic disorder and developmental delay. Journal of Autism and Developmental Disorders, v.27, p.397-413, 1997.

MAIA, A.C.B. Reflexões sobre a educação sexual da pessoa com deficiência. Revista Brasileira de Educação Especial, Marília, v.7, n.1, p.35-46, 2001.

MAIA, A.C.B.; CAMOSSA, D. A. Relatos de jovens deficientes mentais sobre a sexualidade através de diferentes estratégias. Paidéia, Ribeirão Preto, v.12, n.24, p.205-214, 2003.

MINISTÉRIO DA SAÚDE. Resolução n ${ }^{0}$ 196, de 10 de outubro de 1996. Dispõe sobre as diretrizes e normas regulamentadoras de pesquisas envolvendo seres humanos. Conselho Nacional de Saúde, Brasília, 16 out. 1996. Disponível em: <http:/ / conselho.saude.gov.br/ resolucoes/reso_96.htm>. Acesso em: 20 set. 2010.

MONTANARI, P.M. Jovens e deficiência: comportamento e corpos desviantes. In: Ministério da Saúde - Área de Saúde do Adolescente e do Jovem (Org.). Cadernos Juventude, Saúde e Desenvolvimento. Ministério da Saúde, Brasília, 1999. p.97-108

OLIVEIRA, S. L. Tratado de metodologia científica: projetos de pesquisas, TGI, TCC, Monografias, Dissertações e Teses. São Paulo: Pioneira, 1999.

PINEL, A. C. Educação Sexual para pessoas portadoras de deficiências físicas e mentais. In: RIBEIRO, M. (Org.). O prazer e o pensar: orientação sexual para educadores e profissionais de saúde. São Paulo: Gente, 1999. p.211-226.

SCHWARTZMAN, J. S. Síndrome de Down. São Paulo: Memnon, 1999.

SILVA, N. L. P; DESSEN, M. A. Deficiência mental e família: implicações para o desenvolvimento da criança. Psicologia: Teoria e Pesquisa, v.17, n.2, p.133-141, 2001.

THARINGER, D; HORTON, C.B; MILLEA, S. Sexual abuse and exploitation of children and adults with mental retardation and other handicaps. Child Abuse E Negletect, v.14, p.301-312, 1990.

TRINDADE, Z. A.; ANDRADE, A. N. Psicologia e saúde: um campo em construção. Vitória: Casa do Psicólogo, 2005.

VITIELLO, N. A educação sexual necessária. Revista Brasileira de Sexualidade Humana, São Paulo, v.6, n.1, p.15-28, 1995.

Recebido em: 17/10/2011

Reformulado em: 06/06/2012

Aprovado em: 15/08/2012 